\title{
Improved Performance of Hydrothermally Synthesized LiMnPO by Ball Milling as a Positive Electrode for Li Ion Battery
}

\author{
Masashi Kotobuki \\ Department of Material and Environmental Engineering, Hakodate National College of Technology, 14-1 Tokura-cho, Hokkaido, \\ Hakodate 042-8501, Japan \\ Correspondence should be addressed to Masashi Kotobuki; kotobuki@hakodate-ct.ac.jp
}

Received 4 December 2012; Accepted 23 December 2012

Academic Editors: A. I. Bhatt, X. He, A. A. Moya, C. M. Muller, and W. Xing

Copyright (C 2013 Masashi Kotobuki. This is an open access article distributed under the Creative Commons Attribution License, which permits unrestricted use, distribution, and reproduction in any medium, provided the original work is properly cited.

\begin{abstract}
$\mathrm{LiMnPO}_{4}$ is anticipated to be a promising cathode material for next generation lithium battery. A reduction of particle size is recognized as a good strategy to improve its performance and it can be achieved by ball milling. However, the ball milling including carbon addition forms small $\mathrm{LiMnPO}_{4}$ particles with large carbon content, which leads to low volumetric energy density of electrode. In this study, carbon-coated $\mathrm{LiMnPO}_{4}$ prepared by hydrothermal route was applied to the ball milling without carbon addition. The reduction of particle size of carbon-coated $\mathrm{LiMnPO}_{4}$ was achieved by the ball milling without destroying the surface carbon layer. The ball-milled $\mathrm{LiMnPO}_{4}$ particle revealed better cathodic performance than non-milled sample. This was attributed to shortening $\mathrm{Li}$ ion diffusion path, improvement of structural flexibility, and large surface area of electrode due to reduction of particle size. The ball milling is attested to be a promising method to improve cathodic performance of carbon-coated $\mathrm{LiMnPO}_{4}$.
\end{abstract}

\section{Introduction}

$\mathrm{LiMPO}_{4}$ compounds $(\mathrm{M}=\mathrm{Fe}, \mathrm{Mn}, \mathrm{Co}$, and $\mathrm{Ni})$ with olivine structure have been attracted as alternative cathode materials for lithium ion batteries owing to their low cost, low toxicity, chemical and thermal stabilities compared with currently used $\mathrm{LiCoO}_{2}$ [1]. Among these compounds, $\mathrm{LiMnPO}_{4}$ has been recognized the most attractive compound due to its high operation voltage determined by $\mathrm{Mn}^{3+/ 4+}$ redox couple at $4.1 \mathrm{~V}$ versus $\mathrm{Li} / \mathrm{Li}^{+}$and is compatible with the system presently used in lithium ion battery [2].

However, the most serious problem of this cathode material is low intrinsic electronic and $\mathrm{Li}$ ion conductivities $[3,4]$. Various experimental reports have indicated that carbon-coating can provide high electronic conductivity [57]. In fact, a large charge-discharge capacity of carbon-coated $\mathrm{LiFePO}_{4}$ synthesized by a hydrothermal synthesis method has been reported [8].

As for improvement of Li ion conductivity, much effort has been paid for particle size reduction to shorten $\mathrm{Li}$ ion conduction path [9]. Drezen et al. reported reversible capacities for 140 and $270 \mathrm{~nm}$ diameter $\mathrm{LiMnPO}_{4}$ particles prepared by sol-gel method were 81 and $7 \mathrm{~mA} \mathrm{~h} \mathrm{~g}^{-1}$, respectively [10]. Some groups reported a good performance of ball-milled small $\mathrm{LiMnPO}_{4}$ [11] and $\mathrm{LiCoPO}_{4}$ particles [12]. However, their processes included conductive carbon addition ( $\leq 20 \mathrm{wt} . \%$ ) before the ball milling to obtain a carbon composite. This large amount of carbon causes surely improvement of the electronic conductivity, however, such heavy carbon coating decreases volumetric capacity. Additionally, commercial battery foils typically only contain 2.5 weight percent (or lower) carbon blacks with close to 95 weight percent active materiel. Therefore, it may not appeal for practical application.

The carbon coated olivine type cathode materials prepared by hydrothermal route have been reported $[13,14]$. The method allows us to prepare carbon-coated particles readily by only addition of a carbon source to start materials under appropriate condition. Consequently, it is guessed that if carbon-coated $\mathrm{LiMnPO}_{4}\left(\mathrm{LiMnPO}_{4} / \mathrm{C}\right)$ prepared by hydrothermal condition was supplied to the ball milling, carbon amount could be suppressed by omission of further 
carbon addition. On the other hand, harmful influence by the ball-milling of $\mathrm{LiMnPO}_{4} / \mathrm{C}$ is also surmised, such as destroying the carbon coating layer. Hence, research on effect of the ball-milling to $\mathrm{LiMnPO}_{4} / \mathrm{C}$ on electrochemical properties is a worthwhile work.

Herein, we applied to the ball-milling technique to hydrothermally synthesized $\mathrm{LiMnPO}_{4} / \mathrm{C}$ and its electrochemical property was compared with non-milled $\mathrm{LiMnPO}_{4} / \mathrm{C}$ to clarify influence of the ball-milling technique on electrochemical property of $\mathrm{LiMnPO}_{4} / \mathrm{C}$.

\section{Experimental}

$\mathrm{LiMnPO}_{4}$ was synthesized by a modification of hydrothermal process in previous reports for $\mathrm{LiFePO}_{4}$ [15-17]. $\mathrm{MnSO}_{4} \cdot 5 \mathrm{H}_{2} \mathrm{O}(43.84 \mathrm{~g})$ and $\mathrm{Li}_{3} \mathrm{PO}_{4}(20.84 \mathrm{~g})$ were dissolved into purified water $(44 \mathrm{~mL})$ under $\mathrm{N}_{2}$ atmosphere. A molar ratio of $\mathrm{Li}: \mathrm{Mn}: \mathrm{P}$ in a precursor solution was $3: 1: 1$. In order to prepare carbon-coated $\mathrm{LiMnPO}_{4}, 6.00 \mathrm{~g}$ of carboxy methyl cellulose (CMC) was added into the precursor solution [1]. The precursor solution was put into a glass-lined Parr reactor with $\mathrm{N}_{2}$ gas sealed in a stainless steel autoclave, and then heated at $200^{\circ} \mathrm{C}$ for $3 \mathrm{~h}$ with stirring at $680 \mathrm{rpm}$. A precipitation was produced in the reactor under hydrothermal conditions. The precipitation was separated centrifugally at first, and then by a mean of freeze-drying at $-50^{\circ} \mathrm{C}$ for $12 \mathrm{~h}$. Yield was always higher than $95 \%$. The obtained sample was dispersed into ethanol and ball milled at $400 \mathrm{rpm}$ for $12 \mathrm{~h}$ with $\mathrm{ZrO}_{2}$ ball using a planetary ball mill equipment (Pulverissette P-6, Fritsch $\mathrm{GmbH}$ ). The milled and non-milled samples were treated at $700^{\circ} \mathrm{C}$ under $3 \% \mathrm{H}_{2} / \mathrm{Ar}$ flow for $1 \mathrm{~h}$ to obtain electroconductive graphite carbon $[1,14]$.

The crystalline phases of the synthesized sample were identified with X-ray diffraction (XRD, RINT-Ultima, Rigaku) with $\mathrm{Cu} \mathrm{K} \alpha$ radiation. Raman measurement (NRS1000 , JASCO) was carried out at room temperature by a laser radiation of $532 \mathrm{~nm}$. The morphology of the synthesized particle was observed by scanning electron microscope (SEM, JEOL). Coated carbon amount of the samples was estimated by Thermogravimetry (TG) analysis (DTG-60, Shimazu) and BET surface areas of milled and non-milled particles were measured using BELSORP-mini (BEL JAPAN Inc.).

Performances of milled and non-milled $\mathrm{LiMnPO}_{4} / \mathrm{C}$ as a positive electrode were tested by a galvanostatic charge/discharge test. A composite $\mathrm{LiMnPO}_{4} / \mathrm{C}$ electrode was prepared by mixing $\mathrm{LiMnPO}_{4} / \mathrm{C}$, Ketjen black, and Polyvinylidene difluoride (PVdF) in a weight ratio of $90: 5: 5$ in $1.2 \mathrm{~mL}$ of NMP (N-methyl pyrrolidone). The $\mathrm{LiMnPO}_{4} / \mathrm{C}$ electrode was painted onto a thin $\mathrm{Al}$ sheet and dried overnight at $85^{\circ} \mathrm{C}$ under reduced pressure for $12 \mathrm{~h}$. The $\mathrm{LiMnPO}_{4}$ electrode (14 mm diameter) was set in a coin cell 2032 with a mixture of ethylene carbonate (EC) and dimethyl carbonate $(\mathrm{DEC})$ (volume ratio $=1: 1$ ) containing $1 \mathrm{~mol} \cdot \mathrm{dm}^{-3} \mathrm{LiPF}_{6}$ as an electrolyte and with lithium metal as a negative and a reference electrodes. The galvanostatic charge/discharge tests of coin cell with $\mathrm{LiMnPO}_{4}$ positive electrode were performed by using HJ1001SM8A (HOKUTODENKO). In the test, charging process was done under
CC-CV (constant current-constant voltage) mode, that is, charge in a constant current condition of $0.1 \mathrm{C}$ until $4.5 \mathrm{~V}$ and then constant voltage charging was performed at $4.5 \mathrm{~V}$ until current dropped to $0.01 \mathrm{C}$. The discharge process was carried out at constant current condition of $0.1 \mathrm{C}$. Cutoff voltages were $2.0 \mathrm{~V}$ and $4.5 \mathrm{~V}$ for discharge and charge processes, respectively.

\section{Results}

Figure 1 displays SEM images of non-milled and milled samples. In both cases, particles aggregated each other and formed secondary particles. The sizes of primary particles of non-milled and milled samples were estimated to be about 500 and $50 \mathrm{~nm}$, respectively. The particle shapes of both samples were irregular. It is concluded that much smaller particles can be obtained by ball milling. BET surface area of non-milled and milled samples were 8.9 and $49.0 \mathrm{~m}^{2} \mathrm{~g}^{-1}$, respectively. This result is well consistent with SEM observation.

XRD patterns of non-milled and milled samples are depicted in Figure 2. In non-milled sample, all diffraction peaks were attributed to $\mathrm{LiMnPO}_{4}$ with olivine structure and no impurity phase was observed. In milled sample, the diffraction peaks were much broader due to small particle and low crystallinity given by the ball milling. An appearance of new phase was not confirmed. Therefore, it is inferred that the ball milling can crash the $\mathrm{LiMnPO}_{4}$ particles, but did not produce any impurity phase.

The Raman spectroscopy is sensitive to surface of the materials comparing with XRD. Dokko et al. have succeeded in detection of even small amount of impurity on the $\mathrm{LiFePO}_{4}$ synthesized by the hydrothermal process [17] and carbon coating layer on the surface of the $\mathrm{LiFePO}_{4} / \mathrm{C}[8]$, $\mathrm{LiMnPO}_{4} / \mathrm{C}$ [1], and $\mathrm{LiCoPO}_{4} / \mathrm{C}$ [14]. Thus, the Raman measurement was carried out to detect carbon layer on the samples that could not be detected by the XRD measurement. Figure 3 reveals the Raman spectra of non-milled and milled $\mathrm{LiMnPO}_{4} / \mathrm{C}$. In non-milled sample, clear peaks appeared at 948,1361 , and $1610 \mathrm{~cm}^{-1}$. The peak at $948 \mathrm{~cm}^{-1}$ is assigned to the symmetric vibration of the $\mathrm{PO}_{4}$ group [18]. As mentioned above, clear diffraction peaks of the $\mathrm{LiMnPO}_{4}$ were observed in the XRD patterns. The peak at $948 \mathrm{~cm}^{-1}$ was consistent with the result of XRD and it was clear that the $\mathrm{LiMnPO}_{4}$ has been synthesized successfully. Peaks at $1610 \mathrm{~cm}^{-1}$ and $1361 \mathrm{~cm}^{-1}$ were attributed to graphite and disorder carbon (G and D bands), respectively [19], indicating that conductive carbon layer was formed on the surface. In milled sample, the peak at $948 \mathrm{~cm}^{-1}$ was not observed because of small particles and low crystallinity of the milled-sample. A high noise level of the spectrum is also possible reason. As for the $G$ and $D$ bands, they clearly appeared in the spectrum although their intensities became weaker, indicating that surface carbon layer still existed even after crashing the particles by the ball milling. The ratio of $G$ band to $D$ band, that is, quality of the carbon layer, was 1.4 and 1.3 for non-milled and milled samples, respectively. Therefore, the qualities of surface carbon layer of both samples are 


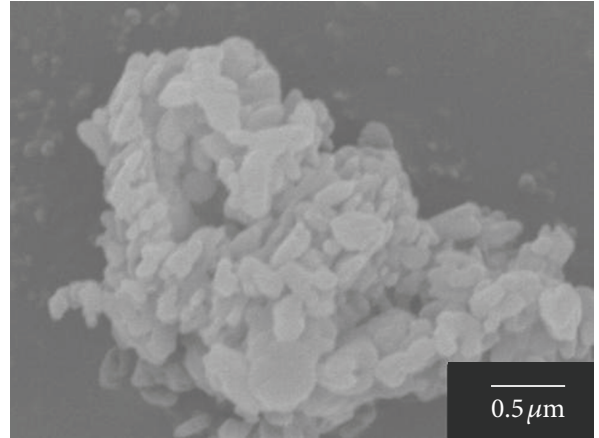

(a) Non-milled $\mathrm{LiMnPO}_{4}$

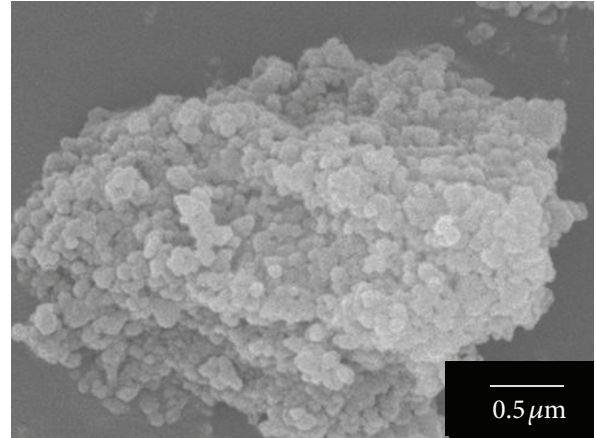

(b) milled $\mathrm{LiMnPO}_{4}$

FIGURE 1: SEM images of the hydrothermally synthesized $\mathrm{LiMnPO}_{4} / \mathrm{C}$. (a) Non-milled and (b) milled samples.

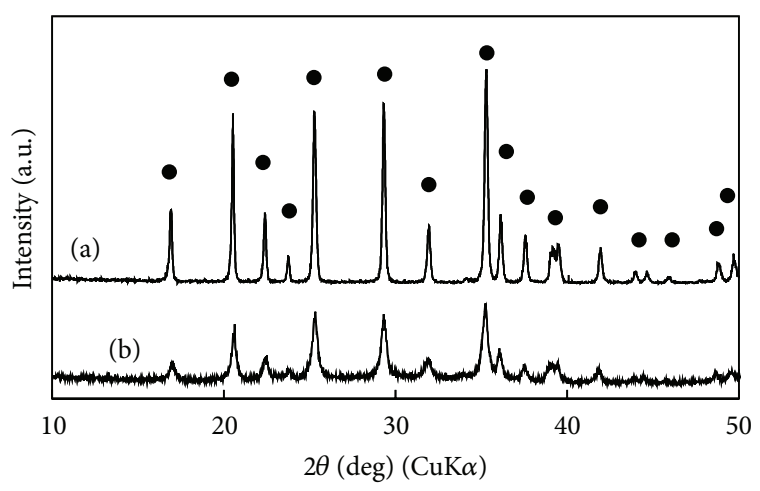

- $\mathrm{LiMnPO}_{4}$

FIGURE 2: XRD patterns of the hydrothermally synthesized $\mathrm{LiMnPO}_{4} / \mathrm{C}$. (a) Non-milled and (b) milled samples.

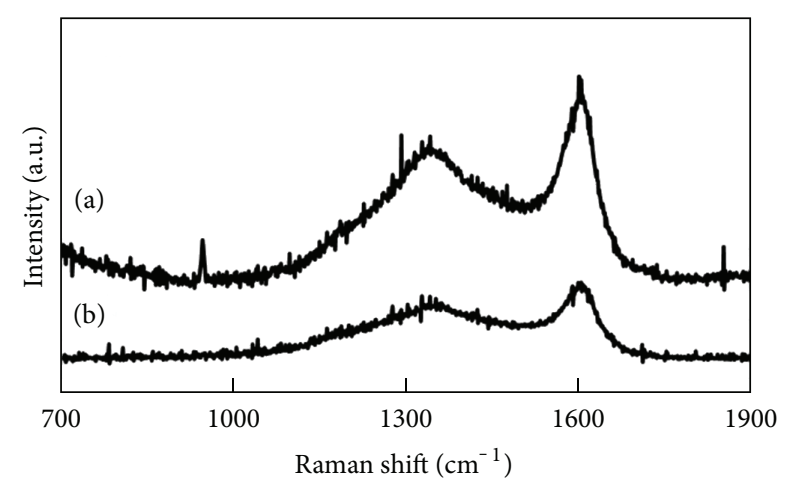

FIGURE 3: Raman spectra of the hydrothermally synthesized $\mathrm{LiMnPO}_{4}$ /C. (a) Non-milled and (b) milled samples.

considered to be same. TG analysis was performed to estimate surface carbon amount. Estimated carbon amounts of nonmilled and milled samples were 3.4 and $2.2 \mathrm{wt} \%$, respectively. It seems that some carbon coatings were destroyed and peeled off during the ball milling.

The charge/discharge test of non-milled and milled $\mathrm{LiMnPO}_{4} / \mathrm{C}$ was carried out (Figure 4 ). In both cases, charge and discharge plateaus at around $4.1 \mathrm{~V}$ versus $\mathrm{Li} / \mathrm{Li}^{+}$, which are attributed to intrinsic redox of $\mathrm{LiMnPO}_{4}$, were observed. In non-milled $\mathrm{LiMnPO}_{4}$, the plateau was much shorter than milled sample and the discharge capacity was $109 \mathrm{~mA} \mathrm{~h} \mathrm{~g}^{-1}$. This was $64 \%$ of theoretical one $\left(171 \mathrm{~mA} \mathrm{~h} \mathrm{~g}^{-1}\right)$ [20]. In milled $\mathrm{LiMnPO}_{4} / \mathrm{C}$, a potential difference of the plateau between charge and discharge curves was small owing to small internal resistance of the milled $\mathrm{LiMnPO}_{4} / \mathrm{C}$ electrode. The discharge capacity improved, $145 \mathrm{~mA} \mathrm{~h} \mathrm{~g}^{-1}, 85 \%$ of theoretical capacity. A rate capability test also revealed favorable performance of milled sample (Figure 5). In this experiment, the charge process was performed at constant current condition of $0.1 \mathrm{C}$. The discharge capacities of milled and non-milled samples at $0.1 \mathrm{C}$ were 127 and $98 \mathrm{~mA} \mathrm{~h} \mathrm{~g}^{-1}$, respectively. Then, the capacity of non-milled sample decreased more quickly, only $6 \mathrm{~mA} \mathrm{~h} \mathrm{~g}^{-1}$ at 5.0 C. On the other hand, the milled sample still maintained high capacity, $64 \mathrm{~mA} \mathrm{~h} \mathrm{~g}^{-1}$ at same $\mathrm{C}$ rate. This corresponded to $50 \%$ of capacity retention.

\section{Discussion}

In this study, we applied the ball milling to hydrothermally synthesized $\mathrm{LiMnPO}_{4} / \mathrm{C}$ and its electrochemical property was compared with non-milled $\mathrm{LiMnPO}_{4} / \mathrm{C}$. By the ball milling, small particle of $\mathrm{LiMnPO}_{4} / \mathrm{C}$ was obtained, although a little loss of surface carbon layer was confirmed. The ballmilled $\mathrm{LiMnPO}_{4} / \mathrm{C}$ demonstrated larger discharge capacity than non-milled $\mathrm{LiMnPO}_{4} / \mathrm{C}$. Fey et al. studied on a dependency of discharge capacity on surface carbon amount of $\mathrm{LiFePO}_{4}$ [21]. They reported the discharge capacities of $\mathrm{LiFePO}_{4} / \mathrm{C}$ with coated carbon from 1.0 to $6.0 \mathrm{wt} \%$ were almost identical. In this study, carbon amounts of nonmilled and milled samples were 3.4 and $2.2 \mathrm{wt}$. \%, respectively. Consequently, it can be said that the carbon layer on the $\mathrm{LiMnPO}_{4}$ particle surface was destroyed a little by the ball milling; however, the deconstruction would hardly influence on electrochemical property. The difference of cathodic performance between non-milled and milled samples seems to be attributed to difference in length of Li ion transport paths by diverse particle size. Also, it is fairly well known that the charged $\mathrm{LiMn}^{\mathrm{II}} \mathrm{PO}_{4}$ phase undergoes a severe lattice 


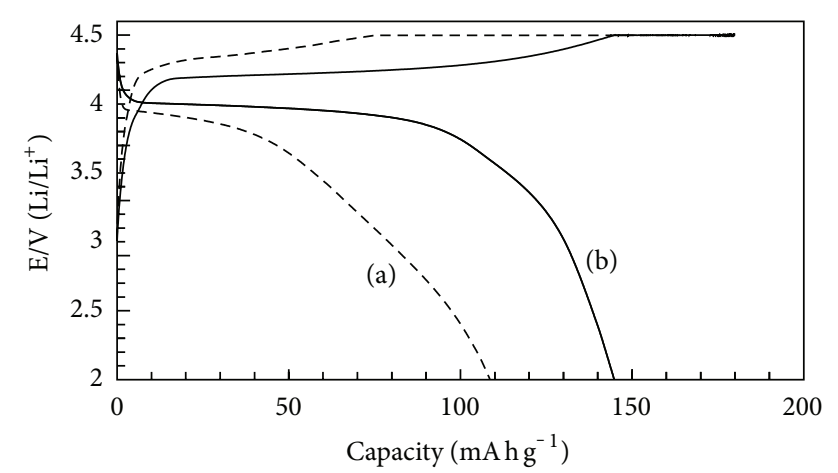

FIGURE 4: Charge and discharge curves of the hydrothermally synthesized $\mathrm{LiMnPO}_{4} / \mathrm{C}$. (a) Non-milled and (b) milled samples.

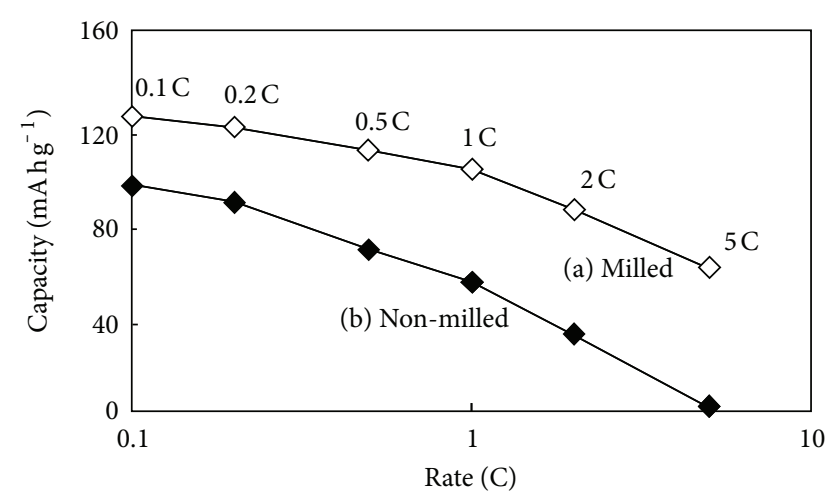

FIGURE 5: Rate capabilities of the hydrothermally synthesized $\mathrm{LiMnPO}_{4} /$ C. (a) Milled and (b) Non-milled samples.

deformation due to the asymmetric electronic configuration of $\mathrm{Mn}^{3+}$ ions $\left(3 \mathrm{~d}^{4}\left(\mathrm{t}_{2 \mathrm{~g}}{ }^{3} \mathrm{e}_{\mathrm{g}}{ }^{1}\right)\right)[22,23]$. The Jahn-Teller deformation as well as the large lattice misfit between $\mathrm{LiMnPO}_{4}$ and $\mathrm{MnPO}_{4}$ phases destroys the integrity of lattice, thus leading to a low electrochemical activity. The small size of $\mathrm{LiMnPO}_{4}$ enhances structural flexibility against lattice deformation [24]. Thus, improvement of integrity of the lattice by structural flexibility of small particles would be also another reason for superior performance of the milled sample. Moreover, the surface area of electrode increased with reduction of $\mathrm{LiMnPO}_{4}$ particle size as indicated by BET surface area measurement, leading to large contact area between electrolyte and electrode. This enlargement of electrode area would also help improved performance of milled sample.

The reduction of $\mathrm{LiMnPO}_{4} / \mathrm{C}$ particle size by the ballmilling was achieved and improved performance of ballmilled $\mathrm{LiMnPO}_{4} / \mathrm{C}$ was confirmed. This is attributed to short Li ion diffusion paths, improvement of structure flexibility, and large surface area of electrode by reduction of $\mathrm{LiMnPO}_{4} / \mathrm{C}$ particle size. The ball milling is attested to be a promising method to improve cathodic performance of carbon-coated $\mathrm{LiMnPO}_{4}$.

\section{Conclusion}

The ball milling was applied to hydrothermally synthesized $\mathrm{LiMnPO}_{4} / \mathrm{C}$. The $\mathrm{LiMnPO}_{4} / \mathrm{C}$ particle size was successfully reduced by the ball milling. Although a little loss of surface carbon layer by the ball milling was observed, this loss did not influence on electrochemical properties. The ballmilled $\mathrm{LiMnPO}_{4} / \mathrm{C}$ demonstrated higher cathodic performance than non-milled sample. This would be attributed to short Li ion diffusion paths, improvement of structure flexibility, and large surface area provided by reduction of $\mathrm{LiMnPO}_{4} / \mathrm{C}$ particle size. The ball milling is proven to be a promising method to improve cathodic performance of carbon-coated $\mathrm{LiMnPO}_{4}$.

\section{References}

[1] Y. Mizuno, M. Kotobuki, H. Munakata, and K. Kanamura, "Effect of carbon source on electrochemical performance of carbon coated $\mathrm{LiMnPO}_{4}$ cathode," Journal of the Ceramic Society of Japan, vol. 117, no. 1371, pp. 1225-1228, 2009.

[2] H. Fang, L. Li, and G. Li, "Hydrothermal synthesis of electrochemically active $\mathrm{LiMnPO}_{4}$," Chemistry Letters, vol. 36, no. 3, pp. 436-437, 2007.

[3] C. Delacourt, L. Laffont, R. Bouchet et al., "Toward understanding of electrical limitations (electronic, ionic) in $\mathrm{LiMPO}_{4}$ $(\mathrm{M}=\mathrm{Fe}, \mathrm{Mn})$ electrode materials," Journal of the Electrochemical Society, vol. 152, no. 5, pp. A913-A921, 2005.

[4] M. Yonemura, A. Yamada, Y. Takei, N. Sonoyama, and R. Kanno, "Comparative kinetic study of olivine $\mathrm{LixMPO}_{4}(\mathrm{M}=$ Fe, Mn)," Journal of the Electrochemical Society, vol. 151, no. 9, pp. A1352-A1356, 2004.

[5] Z. Chen and J. R. Dahn, "Reducing carbon in $\mathrm{LiFePO}_{4} / \mathrm{C}$ composite electrodes to maximize specific energy, volumetric energy, and tap density," Journal of the Electrochemical Society, vol. 149, no. 9, pp. A1184-A1189, 2002.

[6] R. Dominko, M. Bele, M. Gaberscek et al., "Impact of the carbon coating thickness on the electrochemical performance of $\mathrm{LiFePO}_{4} / \mathrm{C}$ composites," Journal of the Electrochemical Society, vol. 152, no. 3, pp. A607-A610, 2005.

[7] J. Moskon, R. Dominko, R. Cerc-Korosec, M. Gaberscek, and J. Jamnik, "Morphology and electrical properties of conductive carbon coatings for cathode materials," Journal of Power Sources, vol. 174, no. 2, pp. 683-688, 2007.

[8] H. Nakano, K. Dokko, S. Koizumi, H. Tannai, and K. Kanamura, "Hydrothermal synthesis of carbon-coated $\mathrm{LiFePO}_{4}$ and its application to lithium polymer battery," Journal of the Electrochemical Society, vol. 155, no. 12, pp. A909-A914, 2008.

[9] C. Delacourt, P. Poizot, M. Morcrette, J. M. Tarascon, and C. Masquelier, "One-step low-temperature route for the preparation of electrochemically active $\mathrm{LiMnPO}_{4}$ powders," Chemistry of Materials, vol. 16, no. 1, pp. 93-99, 2004.

[10] T. Drezen, N. H. Kwon, P. Bowen, I. Teerlinck, M. Isono, and I. Exnar, "Effect of particle size on $\mathrm{LiMnPO}_{4}$ cathodes," Journal of Power Sources, vol. 174, no. 2, pp. 949-953, 2007.

[11] S. K. Martha, B. Markovsky, J. Grinblat et al., " $\mathrm{LiMnPO}_{4}$ as an advanced cathode material for rechargeable lithium batteries," Journal of the Electrochemical Society, vol. 156, no. 7, pp. A541A552, 2009.

[12] M. E. Rabanal, M. C. Gutierrez, F. Garcia-Alvarado, E. C. Gonzalo, and M. E. Arroyo-de Dompablo, "Improved electrode 
characteristics of olivine- $\mathrm{LiCoPO}_{4}$ processed by high energy milling," Journal of Power Sources, vol. 160, no. 1, pp. 523-528, 2006.

[13] H. Nakano, K. Dokko, S. Koizumi, H. Tannai, and K. Kanamura, "Hydrothermal synthesis of carbon-coated $\mathrm{LiFePO}_{4}$ and its application to lithium polymer battery," Journal of the Electrochemical Society, vol. 155, no. 12, pp. A909-A914, 2008.

[14] M. Kotobuki, Y. Mizuno, H. Munakata, and K. Kanamura, "Electrochemical properies of hydrothermally synthesized $\mathrm{LiCopO}_{4}$ as a high voltage cathode material for lithium secondary battery," Phosphorus Research Bulletin, vol. 24, pp. 12-15, 2010.

[15] K. Dokko, K. Shiraishi, and K. Kanamura, "Identification of surface impurities on $\mathrm{LiFePO}_{4}$ particles prepared by a hydrothermal process," Journal of the Electrochemical Society, vol. 152, no. 11, pp. A2199-A2202, 2005.

[16] K. Dokko, S. Koizumi, and K. Kanamura, "Electrochemical reactivity of $\mathrm{LiFePO}_{4}$ prepared by hydrothermal method," Chemistry Letters, vol. 35, no. 3, pp. 338-339, 2006.

[17] K. Dokko, S. Koizumi, K. Sharaishi, and K. Kanamura, "Electrochemical properties of $\mathrm{LiFePO}_{4}$ prepared via hydrothermal route," Journal of Power Sources, vol. 165, no. 2, pp. 656-659, 2007.

[18] A. Ait Salah, A. Mauger, K. Zaghib et al., "Reduction $\mathrm{Fe}^{3+}$ of impurities in $\mathrm{LiFePO}_{4}$ from pyrolysis of organic precursor used for carbon deposition," Journal of the Electrochemical Society, vol. 153, no. 9, pp. A1692-A1701, 2006.

[19] R. L. McCreery, "Carbon electrodes: structural effects on electron transfer kinetics," in Electroanalytical Chemistry, A. J. Bard, Ed., vol. 17, Marcel Dekker, New York, NY, USA, 1991.

[20] W. F. Howard and R. M. Spotnitz, "Theoretical evaluation of high-energy lithium metal phosphate cathode materials in Liion batteries," Journal of Power Sources, vol. 165, no. 2, pp. 887891, 2007.

[21] G. T. K. Fey, Y. G. Chen, and H. M. Kao, "Electrochemical properties of $\mathrm{LiFePO}_{4}$ prepared via ball-milling," Journal of Power Sources, vol. 189, no. 1, pp. 169-178, 2009.

[22] Y. G. Xia, Q. Zhang, H. Y. Wang, H. Nakamura, H. Noguchi, and M. Yoshio, "Improved cycling performance of oxygenstoichiometric spinel $\mathrm{Li}_{1+x} \mathrm{Al}_{y} \mathrm{Mn}_{2-x-y} \mathrm{O}_{4+\delta}$ at elevated temperature," Electrochimica Acta, vol. 52, no. 14, pp. 4708-4714, 2007.

[23] G. Amatuci and J. M. Tarascon, "Optimization of insertion compounds such as $\mathrm{LiMn}_{2} \mathrm{O}_{4}$ for Li-Ion batteries," Journal of The Electrochemical Society, vol. 149, no. 12, pp. K31-K46, 2002.

[24] Y. G. Guo, J. S. Hu, and L. J. Wan, "Nanostructured materials for electrochemical energy conversion and storage devices nanostructured materials for electrochemical energy conversion and storage devices," Advanced Materials, vol. 20, no. 15, pp. 2878 2887, 2008 


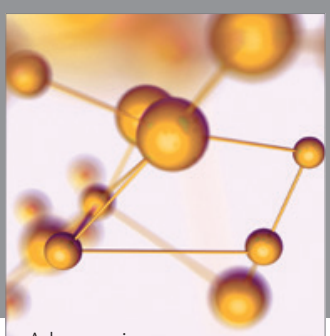

Physical Chemistry
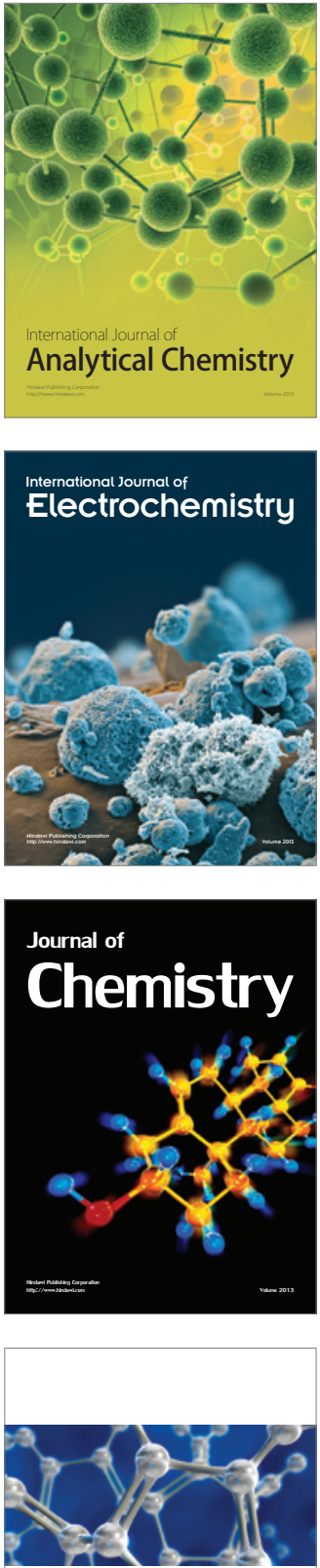

ISRN

Inorganic Chemistry

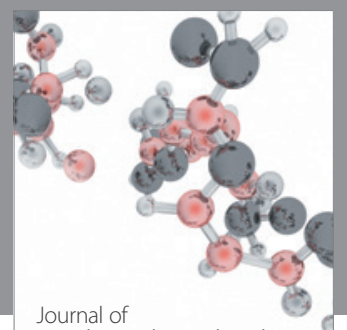

Analytical Methods in Chemistry

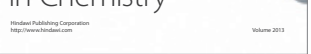

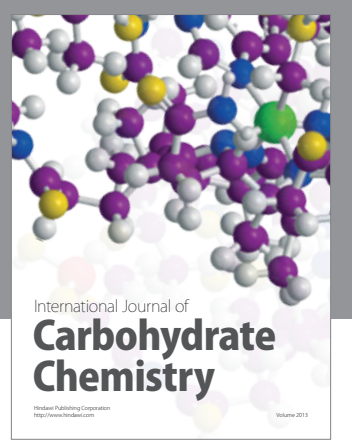
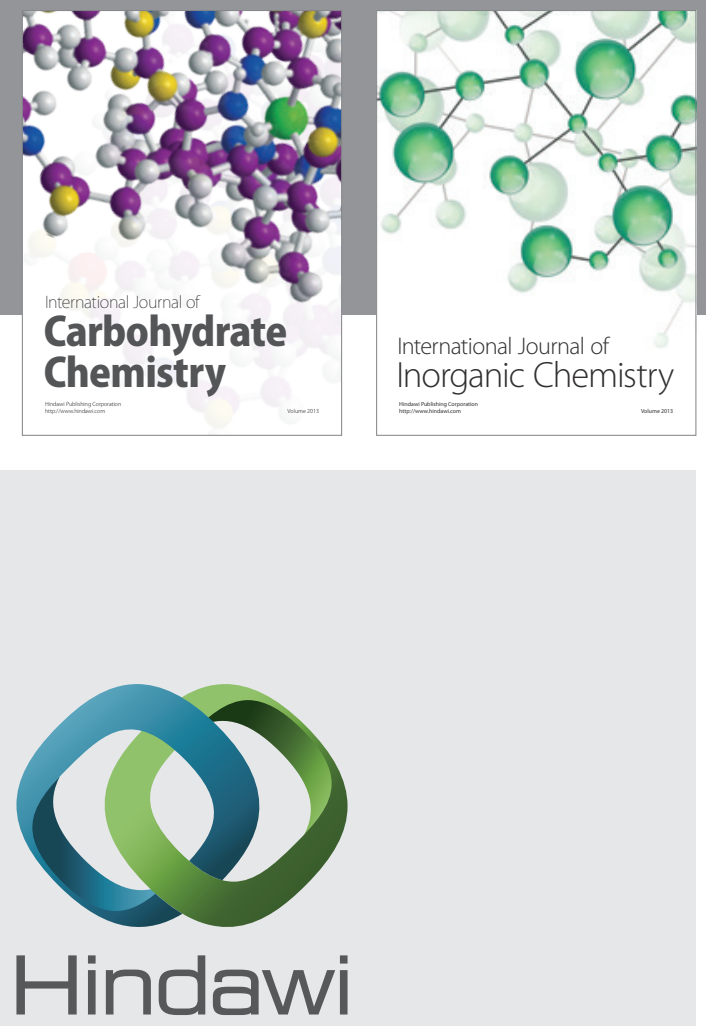

Submit your manuscripts at http://www.hindawi.com
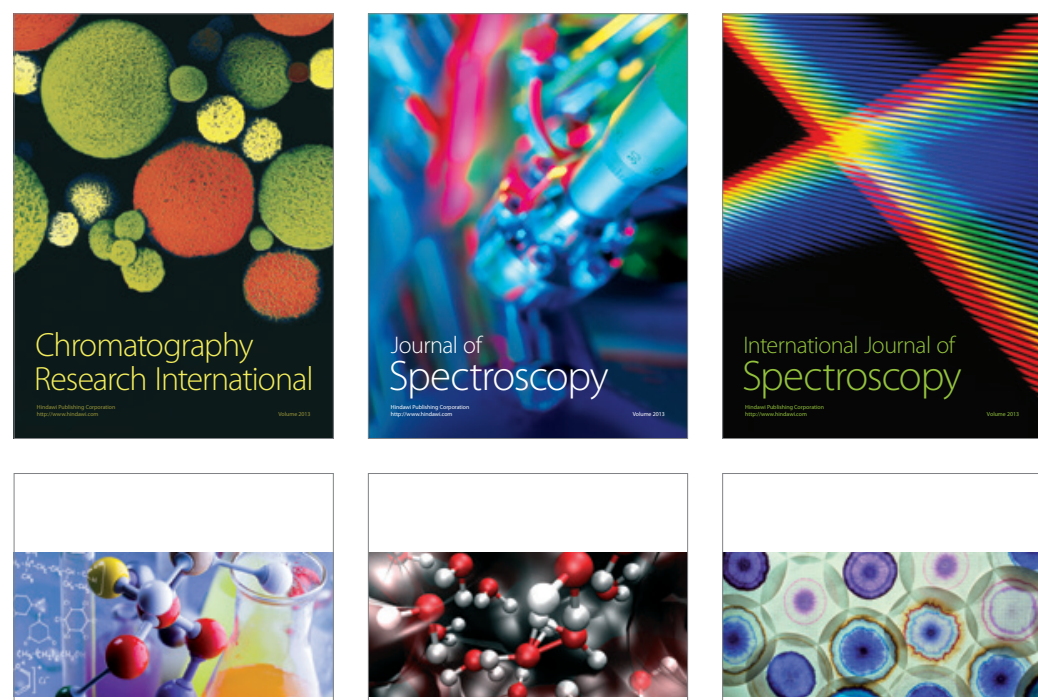

ISRN

ISRN

Organic Chemistry

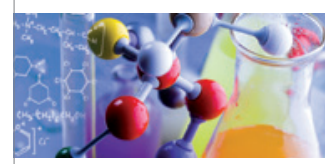

Physical Chemistry

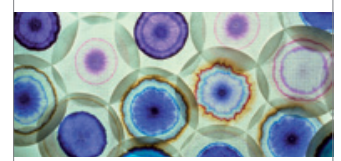

ISRN

Chromatography

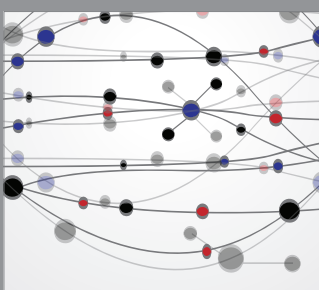

The Scientific World Journal
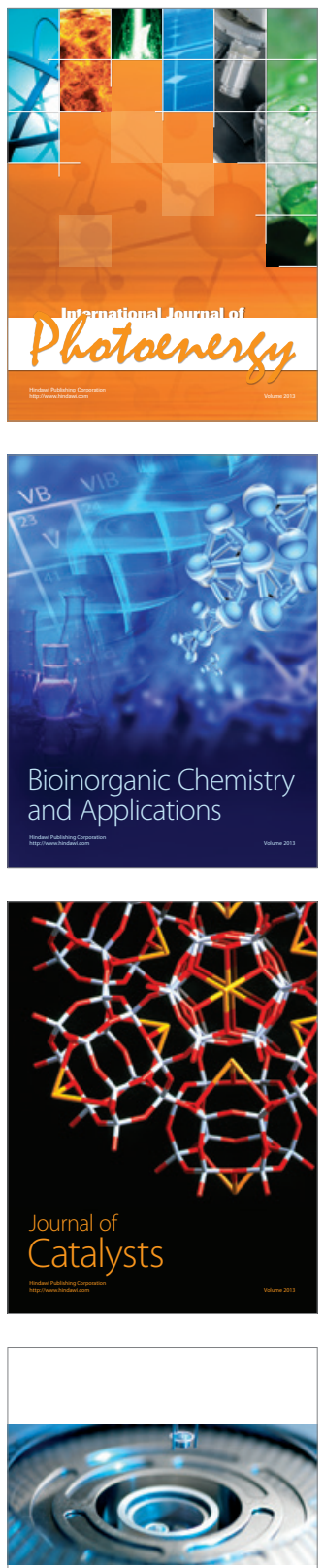

ISRN

Analytical

Chemistry 


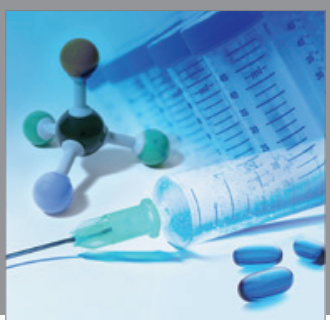

International Journal of

Medicinal Chemistry

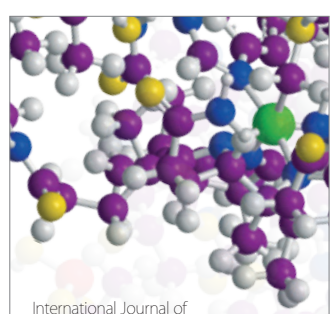

Carbohydrate Chemistry

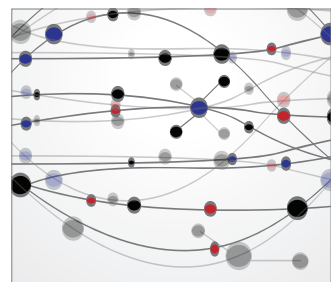

The Scientific World Journal
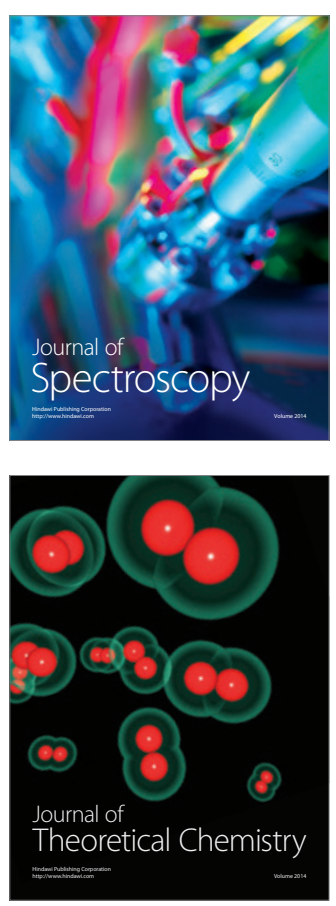
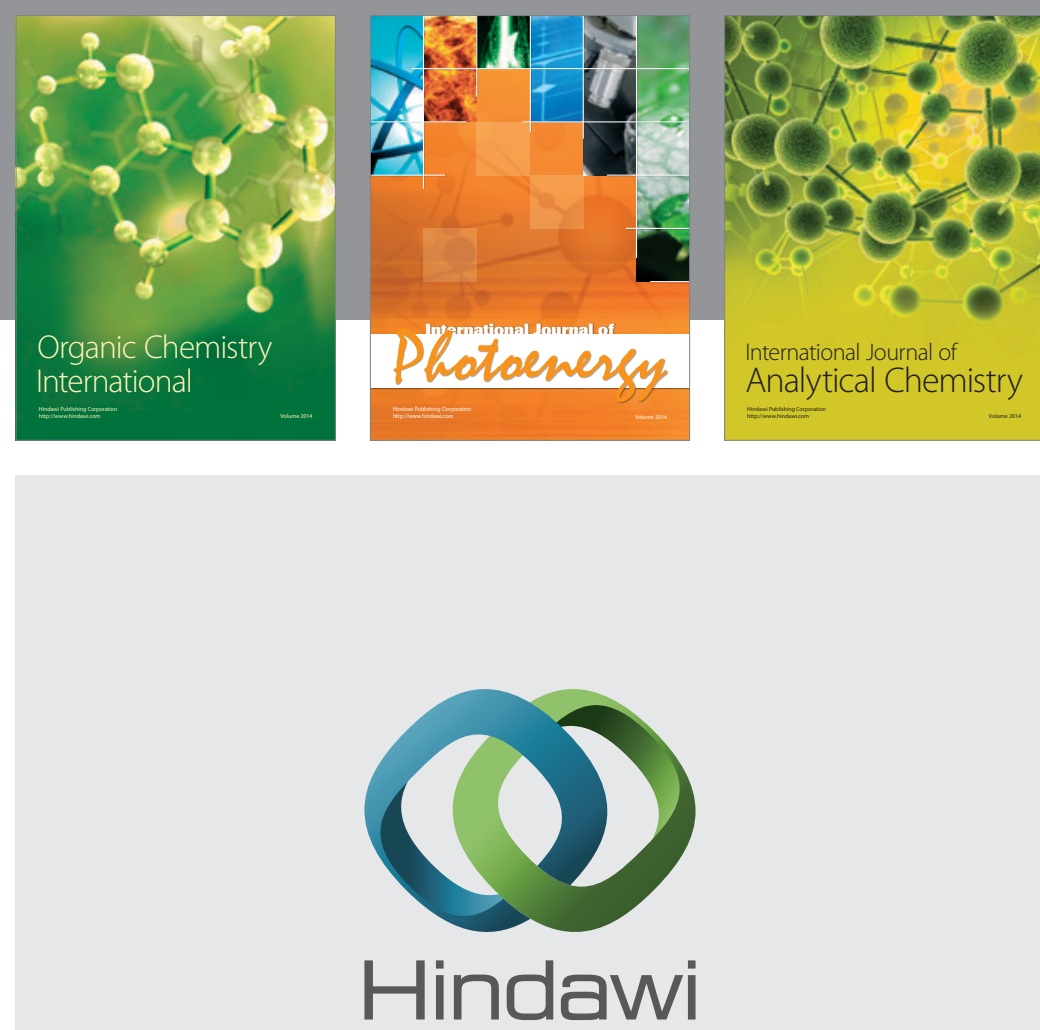

Submit your manuscripts at

http://www.hindawi.com
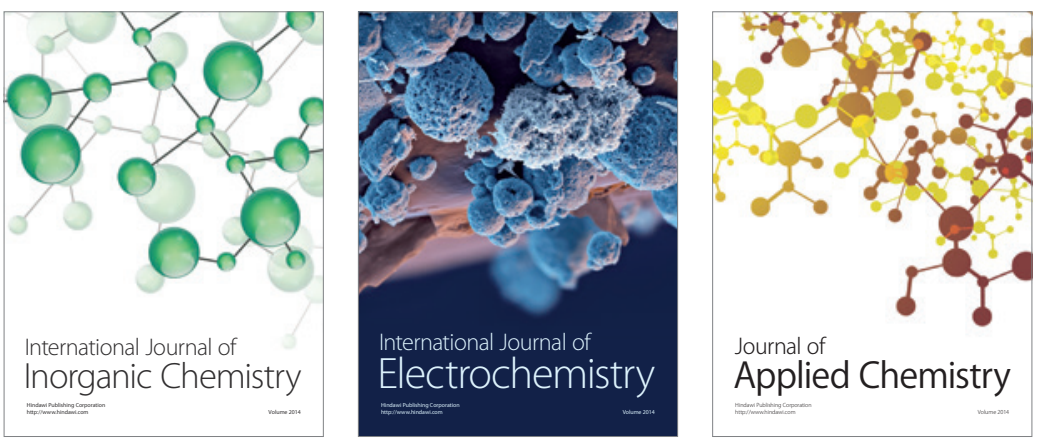

Journal of

Applied Chemistry
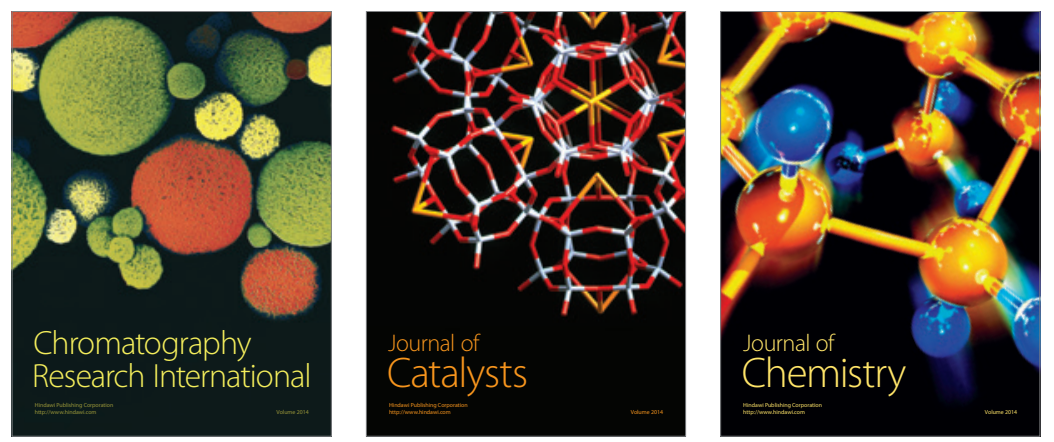
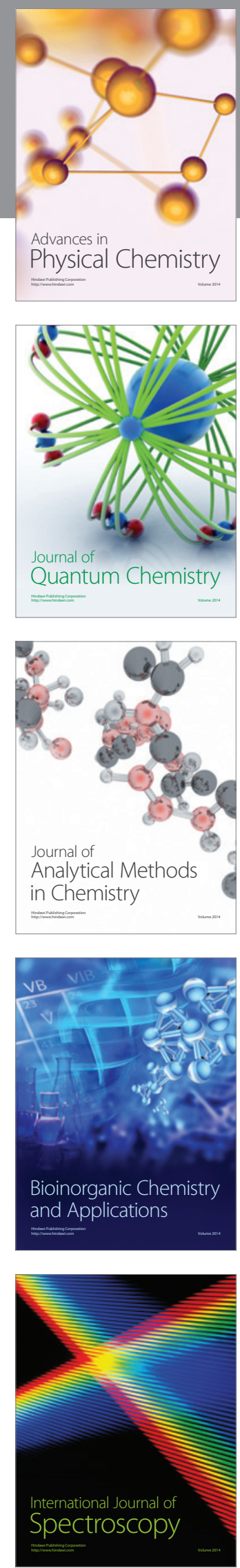